\title{
Effects of ozone-vegetation coupling on surface ozone air quality via biogeochemical and meteorological feedbacks
}

Mehliyar Sadiq et al.

Correspondence to: Amos P. K. Tai (amostai@cuhk.edu.hk)

The copyright of individual parts of the supplement might differ from the CC-BY 3.0 licence. 


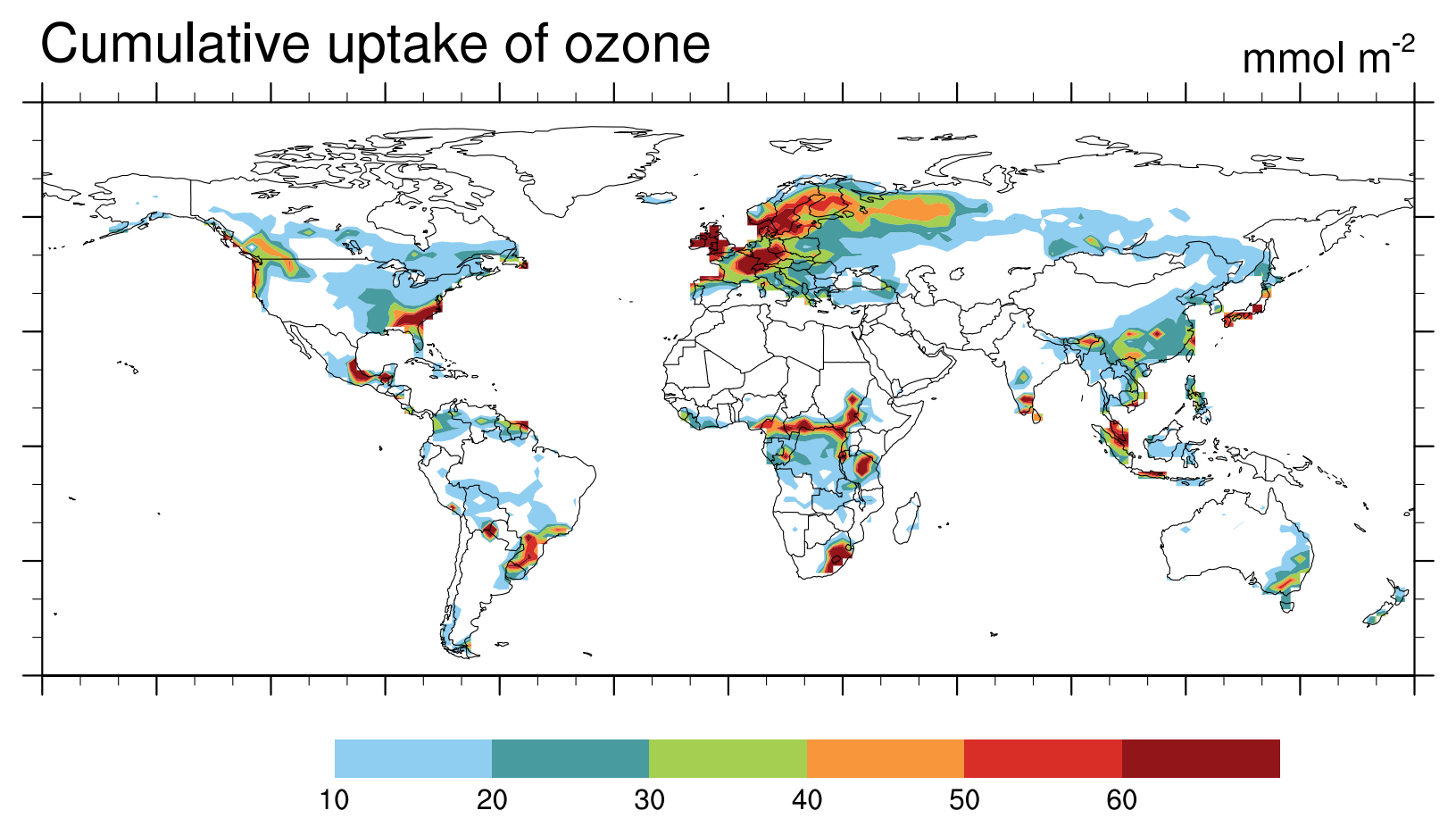

Figure S1. Mean cumulative uptake of ozone (CUO) from the [PHT+COND] case, where ozone uptake simultaneously modifies both photosynthetic rate and stomatal conductance. Results are averaged over the last 15 years of simulations. 
a) $[\mathrm{PHT}+\mathrm{COND}]-\mathrm{CTR}$

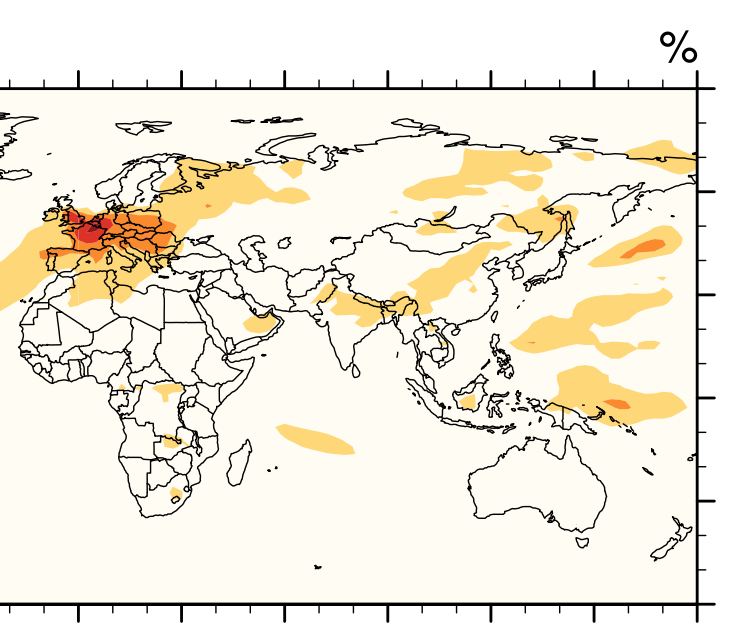

b) COND - CTR

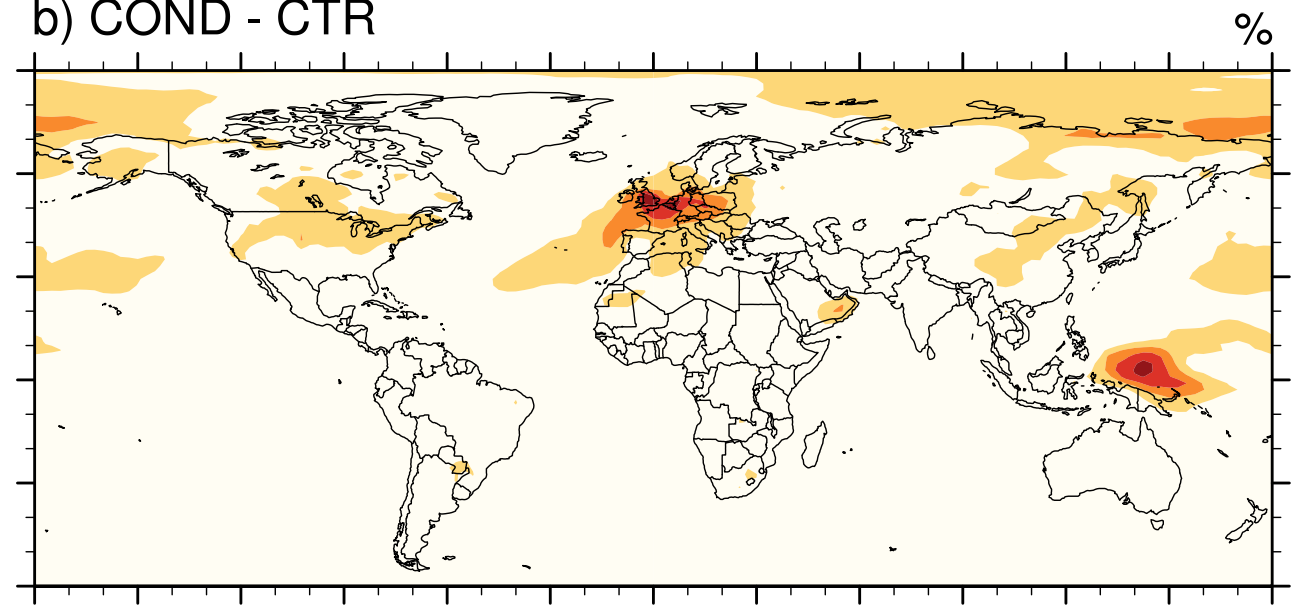

c) PHT - CTR

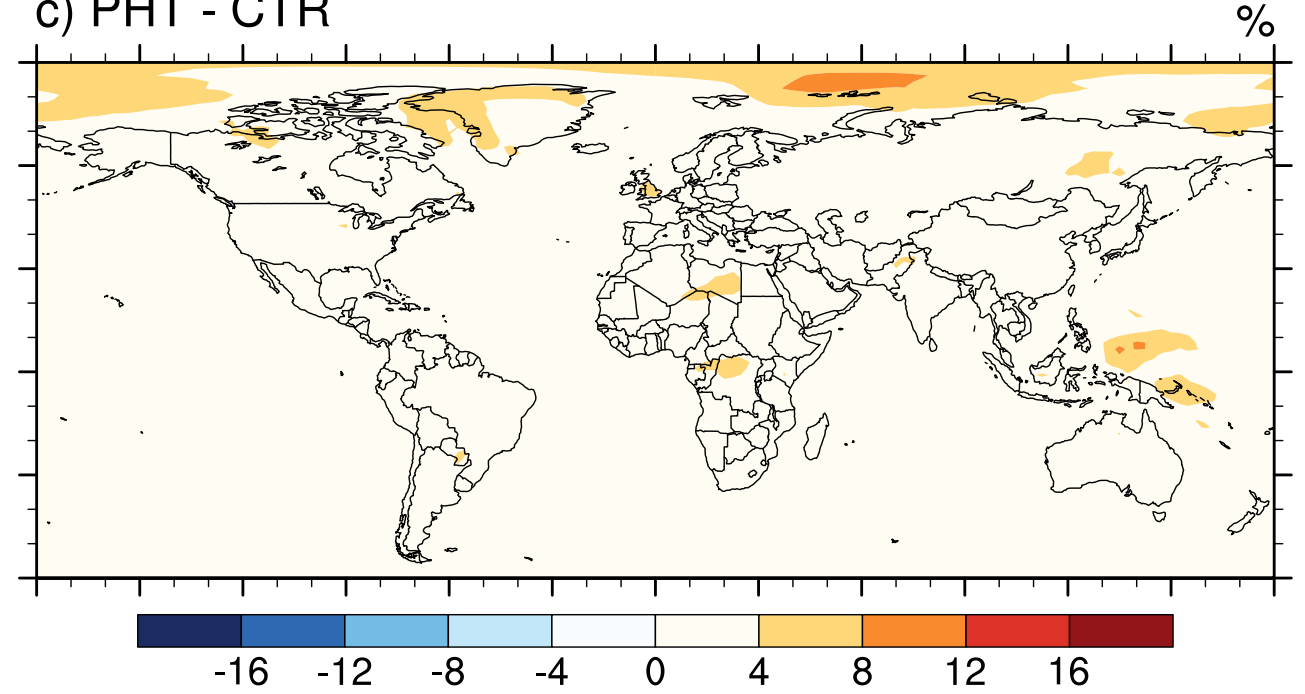

Figure S2. Percentage changes in summertime surface ozone concentrations in different simulations: (a) the case where both photosynthetic rate and stomatal conductance are modified by ozone uptake; (b) modified photosynthetic rate only; and (c) modified stomatal conductance only, all relative to the control case (CTR). 


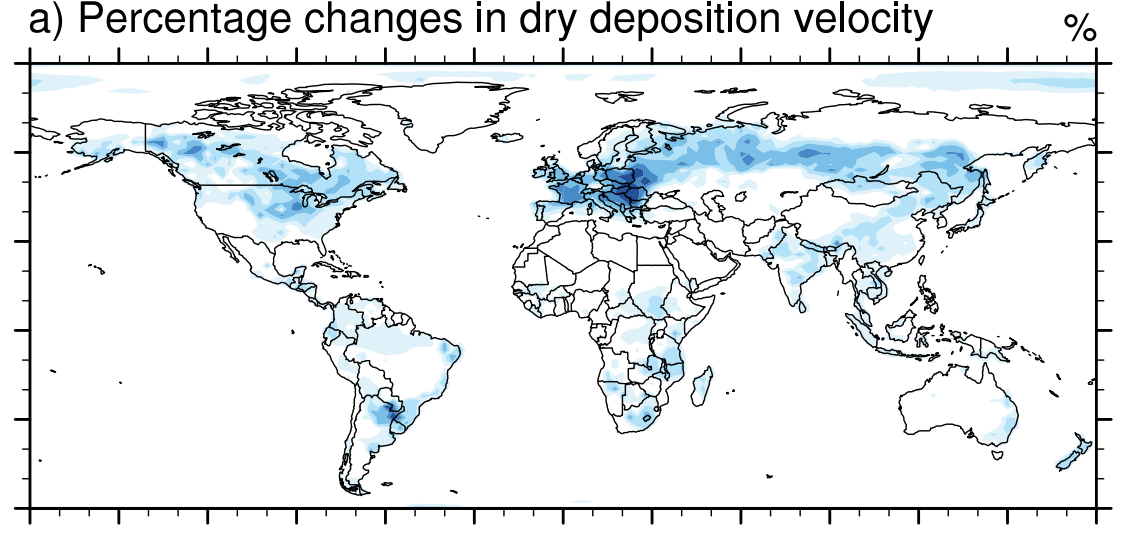

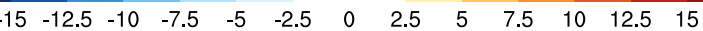

b) Percentage changes in transpiration rate

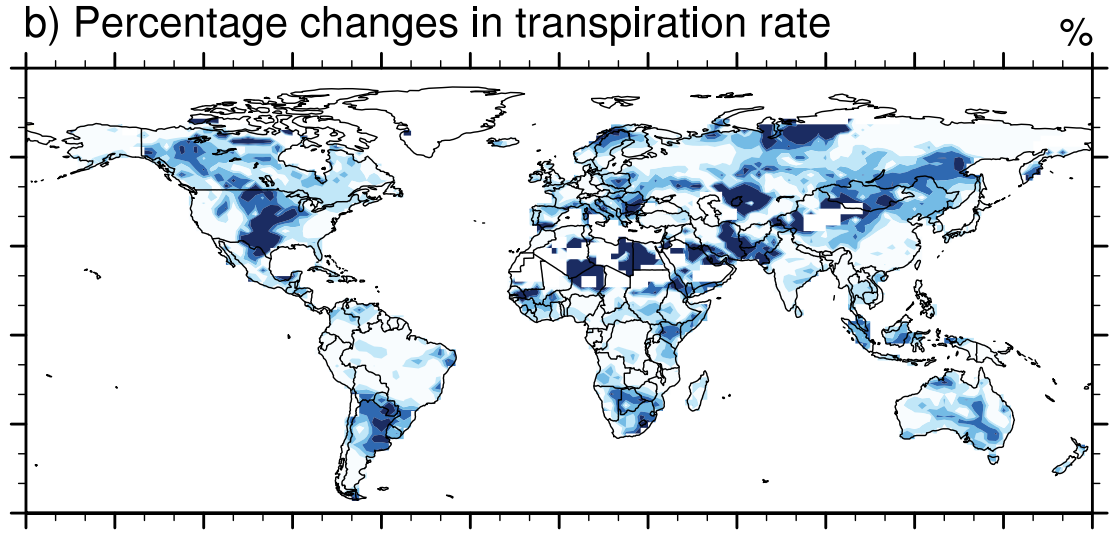

$\begin{array}{lllllllll}-20 & -15 & -10 & -5 & 0 & 5 & 10 & 15 & 20\end{array}$

c) Percentage changes in isoprene emission

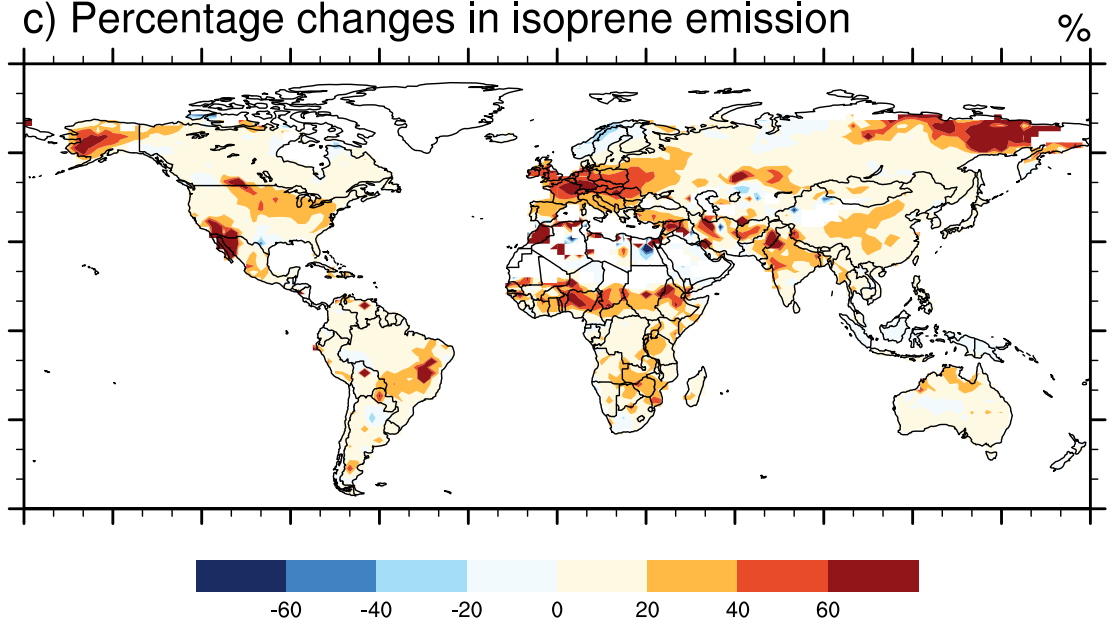

Figure S3. Percentage changes in (a) dry deposition velocity, (b) transpiration rate and (c) isoprene emission in the $[\mathrm{PHT}+\mathrm{COND}]$ case, where both photosynthetic rate and stomatal conductance are modified by ozone uptake, relative to the control case (CTR). 

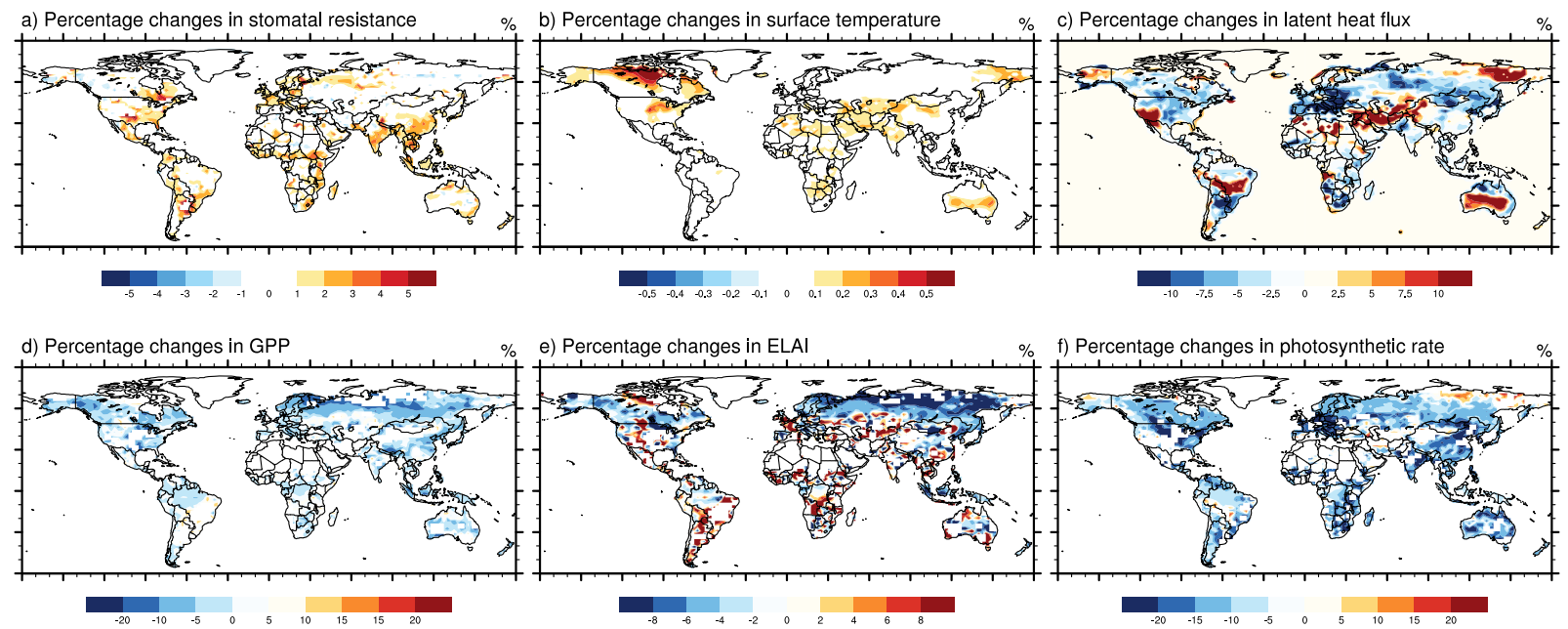

Figure S4. Percentage changes in (a) stomatal resistance, (b) surface temperature, (c) latent heat flux, (d) gross primary production (GPP), (e) effective leaf area index (ELAI) and (f) photosynthetic rate in the $[\mathrm{PHT}+\mathrm{COND}]$ case, where both photosynthetic rate and stomatal conductance are modified by ozone uptake, relative to the control case (CTR). 
a) Percentage changes in soil moisture content
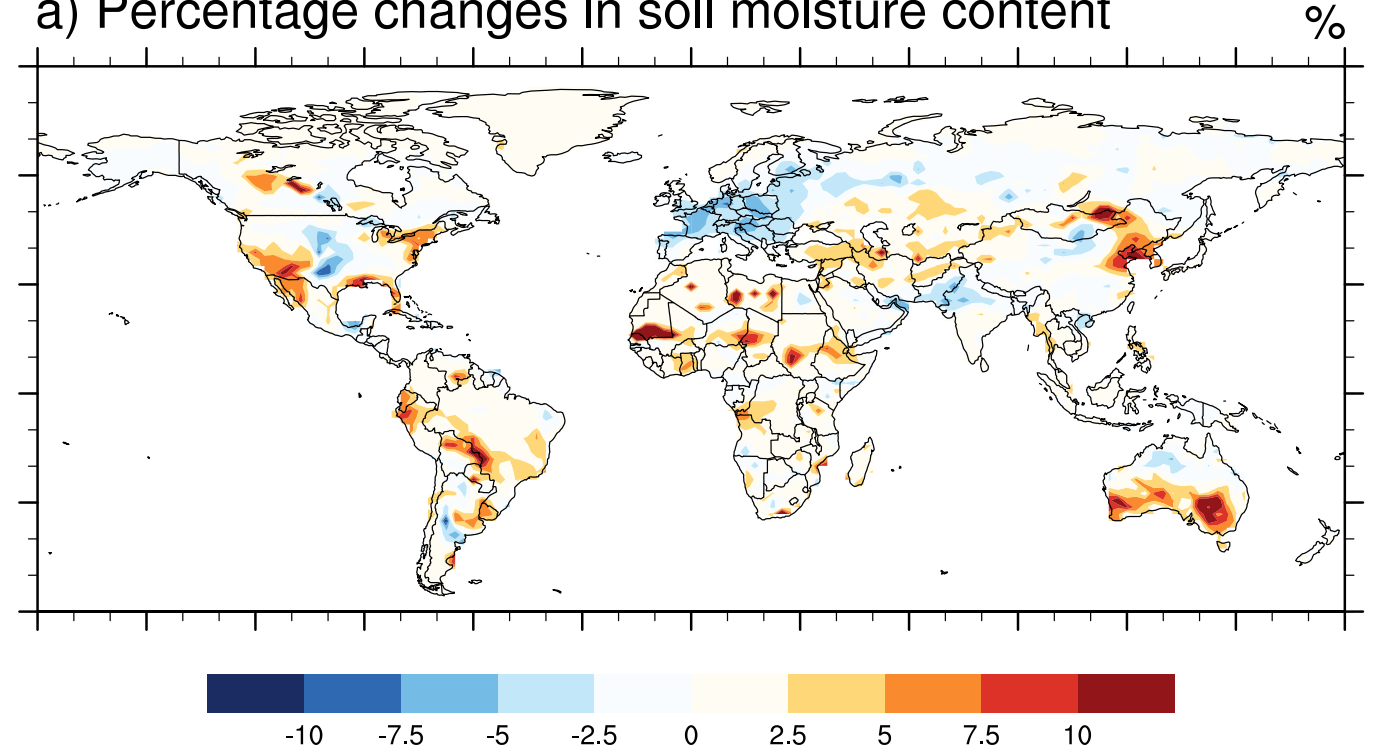

b) Percentage changes in total precipitation

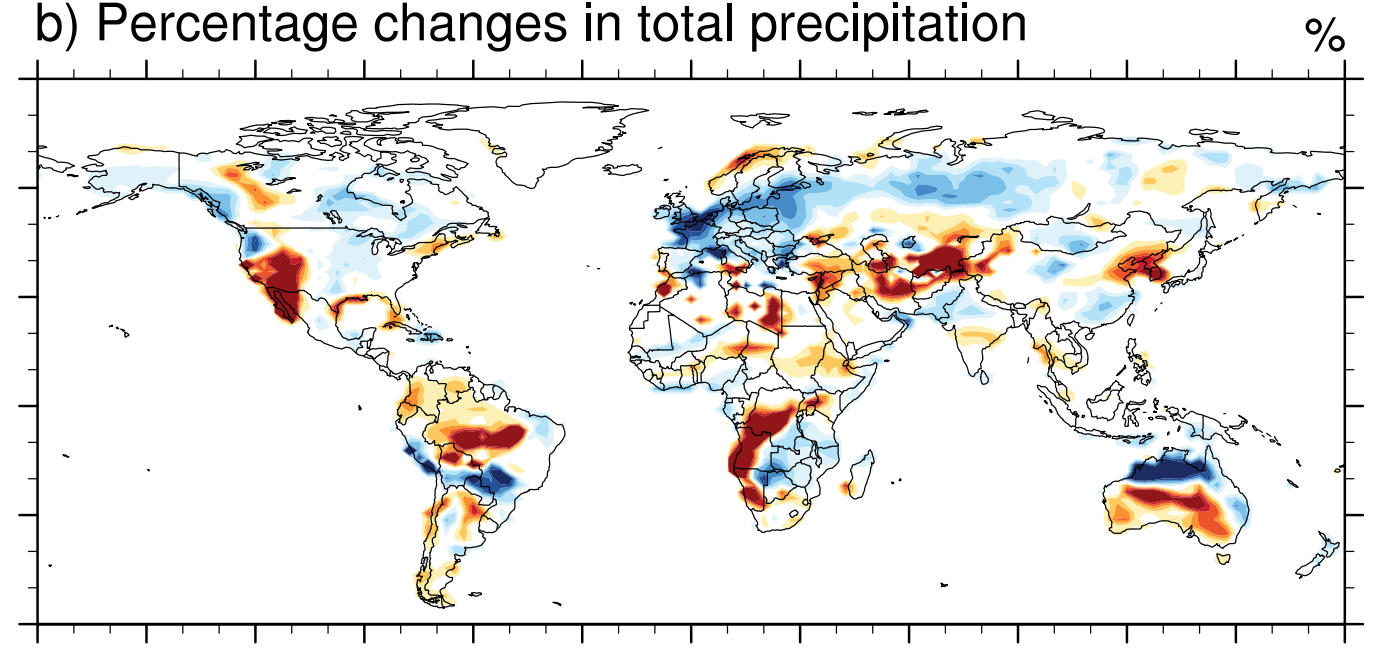

$\begin{array}{lllllllllllll}-30 & -25 & -20 & -15 & -10 & -5 & 0 & 5 & 10 & 15 & 20 & 25 & 30\end{array}$

Figure S5. Percentage changes in (a) volumetric soil water content and (b) total precipitation rate in the $[\mathrm{PHT}+\mathrm{COND}]$ case, where both photosynthetic rate and stomatal conductance are modified by ozone uptake, relative to the control case (CTR). 